\title{
A Survey on M-Learning
}

\author{
P.N.V.Pavan \\ Student, M.Tech \\ VIT University \\ Vellore-632014
}

\author{
Prof. H. Santhi \\ Assistant Professor \\ VIT University \\ Vellore-632014
}

\author{
Prof. N. Jaisankar \\ Professor \\ VIT University \\ Vellore-632014
}

\begin{abstract}
Mobile phones have recently become more common in human's life. Mobile learning can be any time anywhere and any device access information. Mobile learning can be broadly defined as 'the exploring ubiquitous handheld technologies along with wireless and cellular networks, to provide, support, improve and extend the context of teaching and learning. M-learning enables knowledge building by learners in different contexts and enables learners to construct understandings. Mobile technology often changes the way of learning/work activity. The context of mobile learning is more than time and space. To improve learning in distance education, agents are used in mobile nodes by considering user preferences and providing dynamic services. Communication is provided between mobile agents using adhoc networks. Collaborative learning and personalization is also acquired through agents in Mobile Adhoc network. This paper provides an existing survey on developing M-learning. Management and the communication of mobiles in ad hoc networks (MANETs) like Bluetooth or any technology should be considered and also addressing the new learners without any difficulty and providing informal structured courses and programming.
\end{abstract}

\section{General Terms}

Mobile phones, Bluetooth, Communication, Ubiquitous, Technology

\section{Keywords}

Collaborative learning, M-Learning, MANET,

Mobile Agents, Mobile technology.

\section{INTRODUCTION}

Mobile learning is an application of mobile computing to the education. The integration of mobile devices, wireless communication and networking technologies into the education environment could enhance the learning [2]. Mobile devices enable the teacher and students to utilise the computing power anytime and anywhere [18], while the internet and wireless technologies enable mobile devices to interconnect with other computing devices seamlessly. Multiple agents are developed to provide collaborative environment between mobile nodes [1]. Efficient data delivery is achieved without any delay using adhoc network. Agents and MANET support both heterogeneous environment and for taking user preferences and providing feedback to the teacher. A Mobile Ad-hoc Network (MANET) is a self configuring network composed of mobile nodes without any fixed infrastructure [14]. In a MANETs, there is no difference between a host node and a router i.e., all nodes can be source as well as forwarders of traffic. Moreover, all MANET components can be mobile. Oracle database brings new features to improve scalability, reliability, performance and availability.

\subsection{Definition}

Mobile learning can be broadly defined as the ability to learn independently with place and time, provided by a range of mobile devices [12]. M-learning is a term to cover a complex array of possibilities provided by the combining new mobile technologies, wireless infrastructure and e-learning developments [13]. As with any developing paradigm, there are many assumptions to define its main role. There are some definitions that are part to the term m-learning.

1. M-Learning is the combination of mobile computing and e-learning that is resource can be accessible from any place, efficient searching abilities, good interaction, support for effective learning, and performance-based assessment. ELearning is independent of location, time or space [13].

2. Novel m-learning architectures will provide creation, brokerage, delivery and tracking of learning and information contents, using ambient intelligence, location-dependence, personalisation, multi-media messaging (text, video) and distributed databases.

3. Three ways as learning can consider mobile learning in terms of space, mobile in different areas of life, mobile with respect of time [13].

\subsection{Evolution of M-Learning}

M-learning is improved technology for existing e-learning technology and m-learning is evolved using different technologies like LMS, Pod casts, Mobiles etc.., Mobile learning is changed to be using GPRS technology, Bluetooth and different objects can be used for the interaction between different persons, spontaneous response, it is light weight devices, involving in realistic situation and collaborative in nature.

M-learning provides instant student to student communication, synchronous and spontaneous communication, flexible informal communication [13] that is any audio or video as multimedia communication can be achieved and there is no geographic boundary.

M-learning facilitates synchronous and asynchronous performance and improvement dependent grading.

M-learning is considered as blended learning approach that any university can view all learning process. It is basis to improve wider learning practice [13] for providing courses learning. It is evolved for non traditional learners and student that cannot attend classroom for learning.

M-learning is evolved for enhancing literacy and numeracy skills [13] and is used for both independent and collaborative learning strategies, and provides assistance and support to the learners.

M-learning is evolved as personalised learning and is situated, collaborative and ubiquitous learning. 


\subsection{Benefits of M-learning}

- Mobile learning facilitate learners to develop their literacy [12] and different skills and to compare with their existing capabilities

- Mobile learning provides both independent and collaborative learning practices.

- Mobile learning gives learners to recognize places that they need assistance and support.

- Mobile learning facilitates to remove some of the formality from the learning experience and gives activities to unwilling learners

- Mobile learning helps learners to focus more time on learning process.

- Mobile learning helps to improve self-esteem [12]

- Mobile learning helps to improve self-confidence [12].

- Students can study anywhere they have access to the mobile and Internet connection

- $\quad$ Self-paced learning modules allow students to work at their own pace

- Flexibility to join discussions through mobile at any hour or with classmates and instructors remotely in chat rooms

\subsection{M-learning using MANET}

A Mobile Ad-hoc Network (MANET) is a self configuring network composed of mobile nodes without any fixed infrastructure provides efficient data delivery without any delay using Adhoc network. Moreover, all MANET components can be mobile.

M-learning is used for providing collaboration between students and tutors in different contexts using MANETs. Mobile Ad Hoc Networks (MANETs) are used to support communication and collaboration between students. Mlearning utilize different mobile technologies along with the MANETs for providing education to the learners any time anywhere. MANETs use the networks with different ranges. So, mobile phones can connect with each other in approximate.

Using the MANET for $\mathrm{m}$ - learning reduces the communication cost compared to other technologies like 3G. Management and the communication of mobiles using ad hoc networks (MANETs) like Bluetooth can also be considered.

Mobile phones using MANET for communication do not have the need of connecting to internet. As in the present world society,[18] network is formed and people any time any where can interact and need not know whether they are in proximity. Implementing m-learning using MANET is also simple task.

This paper is organized as follows:

I. Describes about the related work of m-learning.

II. Describes about the comparative statement of $\mathrm{m}$ learning.

\section{RELATED WORK}

Rohit Kumar et al proposed that role of reflection in simulation [4] with different student cognitive behaviour is observed and based on the effect of learning, different simulation is made.

Architecture of adaptive collaborative learning is formed. Students communicating each other through chatting or any will obtain reflection with the use of agents. Agents make the students discussions with each other by questioning, conversing. This observes student inter subjective nature. This observation finds differences in interpretation of students and their understandings and their inferences. Chat logs and questions given to them will have the improved observation on collaborative learning [4].

Sourish Chaudhuri et al proposed that students perform tests like pre test and post test [5] gaining conditions with binary logistic regression for comparing the different frequencies. Different conditions and comparative discussion is considered. It contains pointer and Minilesson conditions, Knowledge Construction Dialogue (KCD) [5]. As the conditions are considered as students are not able to attend material correctly.

Transaction between students is decreased during the discussion in collaborative nature. Here agents are used for instructional content for collaborative learning. Collaborative discussion with respect to conversational activities [5] along with the four conditions is considered for analysis.

Hua Ai et al proposed agents that provide collaborative interaction between students [6], which manipulate each agent individually against the social capability [6] and to know about the impact on learning and understandings.

Few differences are obtained for student personalization and tutor performance. By different questions student behaviour are obtained. Conversation between computers will have different biases that affect interactions and perceptions [6]. Conversational agents are developed to communicate with students through the social interface for gaining student perceptions and cognitive behaviour [6]. Individual actions are taken and observed at a level. The results are characterized to find out any biases. This also finds conflict and negotiation among the students during learning. Process of collaboration is made to identify actions or tasks that are useful for formalized and augmented learning [6]. Essential differences of student behaviour are obtained. Based on this desired tutor behaviours are made to help the students in conversation for learning.

Sourish CHAUDHURI et al proposed collaborative design using basilica framework [19] that performs agreement between environmental friends by instructional support. This support is given to the collaborative learning environment by conversational agents which is effective for solicit situations. Tutorial dialogue agents for dynamic collaborative learning are used here. As learning success analysis is more when there is a presence of conversational agents in collaborative learning. Students do not interact more freely with agent compared to the one to one interaction. Basilica framework provides rapid prototyping [19] of collaborative learning. Whether Dialogue based instruction support will be more useful in dynamic collaborative learning environment for solicit and unsolicited situations [19]. Dialogue agents are used for collaborative learning only when request of learning from students is explicit.

Rohit Kumar et al proposed problem solving interface which produce different results during the environment of collaborative learning with dialogue agents [7] for creating collaborative behaviour between students and also for delivering instructions.

Collaborative learning environment with inclusion of conversational agents is compared with without agents. It is declared that with conversational agents is effective because it changed the perception and receiving of materials to the students [7]. Cognitive based conversational agents were programmed by using TuTalk dialogue agent authoring tool 
[7]. Assessment is made by questionnaire process to the students on collaboration, help received, self competence and help provided.

Alf Inge Wang et al describes framework that used to develop mobile collaborative applications [8] in J2ME. It focuses on concepts, design from applications developed using this framework

Technology used in this paper is Personal Area Network (PAN) [8] which provides support for within place and within time collaboration over mobile phones. PAN will be available for wider range of communication and spontaneous interaction. As Bluetooth APIs [8] is lack of high level device to device primitives. So, technical aspects are considered than the collaboration activities. Computer Supported Cooperative Work is made as a research, so that efficient synchronization and best knowledge capability [8] should be achieved. Mobile Collaboration framework is used and Handshake protocol is also used for connection synchronizing and communication mechanism [8].

Vanja Garaj proposed different ways of learning for students of university. Scope of m-learning applications is increased to enhance student knowledge [3] and expertise by using Multimedia Technology and Design (MMTD) [3].

Scope of functionality of m-learning applications at the university level is administration, presentation, feedback, motivation and innovation [3]. Here in the university, based on the course, groups are divided and MMTD is applied for the students to refine their thinking and combine them into one m-learning application. MMTD course is used for learning to give positive effect to the education [3].

Dan Bohus et al proposes framework, RavenClaw, approach based, activity independent dialog management system. This framework is used to construct large number of systems such as: information access, assistance through methods and command management [9].

RavenClaw dialog management framework is developed as successor of earlier CMU communicator project [9], which is also dialog management system. This framework isolates domain specific views of dialog control logic with domain independent methods [9]. This separation will improves the reusability, portability and reduce the development effort. This framework will achieve asynchronous, task independence, flexibility, transparency, modularity and reusability, scalability [9] and open source features. Team Talk project [9], which provide multi participant conversation. In this situation more agents are required simultaneously for conversation.

Yonghong Zhang et al propose mobile learning from anywhere using different devices such as mobiles, PDAs and laptops [10]. Technology that is used in this paper is Bluetooth that connects instantly through Adhoc fashion [10]. Student feedback, their participation in class and answer to tutor is obtained.

In this, architecture is designed, which is based on client server architecture. In this client can be mobile, PDA and server can be laptop, desktop. Medium between them is Bluetooth. Connection will be obtained to out of range server through other nearby device as Adhoc fashion. Bluetooth based learning system, which allows outside environment to be interactive [10]. That is one instructor surrounded by many students.

Hua-Yi Lin et al proposes cluster based m-learning architecture for dynamic learning groups [11] and use different MPEG-21 approaches to achieve.

Cluster approach is followed as all the devices are connected to instructor and formed as one cluster and each cluster can communicate each other if mobile is in out of range. MPEG21 approach [11] is used to solve the problem of compatibility of different multimedia content on mobile browser without using multiple players that make MPEG-21 standard as one for playing different multimedia content on mobile devices. Cluster structures are formed for dynamic learning, that the student access materials from m-centre [11] without any access point and internet connection. In turn, MPEG-21 is developed for different media and future work would be this should be expanded to many mobile devices.

Table1. Comparative Study on Existing Techniques of M-Learning

\begin{tabular}{|c|c|c|c|}
\hline Paper title & Technique used & Merits & Demerits \\
\hline $\begin{array}{c}\text { Tutorial Dialogue as Adaptive } \\
\text { Collaborative Learning Support [4]. }\end{array}$ & $\begin{array}{l}\text { Dialogue agents [4] are used } \\
\text { for delivering content and } \\
\text { simulation }\end{array}$ & $\begin{array}{l}\text { Dialogue agents are } \\
\text { dynamic in nature. }\end{array}$ & $\begin{array}{c}\text { Dialogue agent's architecture } \\
\text { leads to significantly no } \\
\text { support. }\end{array}$ \\
\hline $\begin{array}{c}\text { It's Not Easy Being Green: } \\
\text { Supporting Collaborative “Green } \\
\text { Design" Learning [5]. }\end{array}$ & $\begin{array}{c}\text { Cycle Pad [5] articulate } \\
\text { simulator which makes } \\
\text { students to deliver the content } \\
\text { using graphical interface } \\
\text { widgets. }\end{array}$ & $\begin{array}{l}\text { Dialogue agents are } \\
\text { dynamic in nature. } \\
\text { Frequency of students can } \\
\text { be easily compared by } \\
\text { conditions to obtain the } \\
\text { behaviour. }\end{array}$ & $\begin{array}{l}\text { Dialog agents provide less } \\
\text { interactive support than non- } \\
\text { interactive support. }\end{array}$ \\
\hline $\begin{array}{l}\text { Exploring the Effectiveness of } \\
\text { Social Capabilities and Goal } \\
\text { Alignment in Computer Supported } \\
\text { Collaborative Learning [6]. }\end{array}$ & $\begin{array}{c}\text { These agents can fight with } \\
\text { issue on biases in conversation } \\
{[6] .}\end{array}$ & $\begin{array}{l}\text { This framework is used } \\
\text { for dynamic environment. }\end{array}$ & $\begin{array}{l}\text { Tutor behaviour is very less in } \\
\text { interacting with the student. }\end{array}$ \\
\hline $\begin{array}{l}\text { Engaging Collaborative Learners } \\
\text { with Helping Agents [19]. }\end{array}$ & $\begin{array}{l}\text { Dialogue agents are used for } \\
\text { collaboration. Tutorial dialog } \\
\text { support [19] is also used for } \\
\text { dynamic learning. }\end{array}$ & $\begin{array}{l}\text { Agents are well suited for } \\
\text { conversation in } \\
\text { collaborative } \\
\text { environment. }\end{array}$ & $\begin{array}{l}\text { Dialog agents are given only } \\
\text { when the request is explicit. }\end{array}$ \\
\hline $\begin{array}{c}\text { The RavenClaw dialog } \\
\text { management framework } \\
\text { Architecture and systems [9]. }\end{array}$ & $\begin{array}{l}\text { RavenClaw dialog engine [9] } \\
\text { is used to made more number } \\
\text { of systems interacting }\end{array}$ & $\begin{array}{l}\text { This framework provides } \\
\text { development of mobile } \\
\text { collaborative applications. }\end{array}$ & $\begin{array}{lcr}\text { Student } & \text { prompts } & \text { the } \\
\text { instructional } & \text { material } & \text { which }\end{array}$ \\
\hline
\end{tabular}




\begin{tabular}{|c|c|c|c|}
\hline & & & affects student behaviour [7]. \\
\hline $\begin{array}{l}\text { M-Learning in the Education of } \\
\text { Multimedia Technologists and } \\
\text { Designers at the University Level: } \\
\text { A User Requirements Study [3]. }\end{array}$ & $\begin{array}{l}\text { This provides different } \\
\text { multimedia technologies and } \\
\text { administration [3]. }\end{array}$ & $\begin{array}{l}\text { MMTD to make the } \\
\text { content presented as } \\
\text { visual and creative content } \\
\text { [3] for easy } \\
\text { understandable. }\end{array}$ & $\begin{array}{l}\text { This technology does not } \\
\text { provide full fledged mobile } \\
\text { peer2peer networks [8]. }\end{array}$ \\
\hline $\begin{array}{c}\text { A PEER-TO PEER } \\
\text { FRAMEWORK FOR MOBILE } \\
\text { COLLABORATION [8]. }\end{array}$ & $\begin{array}{l}\text { Conversational agents for } \\
\text { having independent learning. } \\
\text { Low range PANs [8] are used } \\
\text { for Mobile Computer } \\
\text { Supported Collaborative } \\
\text { Work. }\end{array}$ & $\begin{array}{l}\text { Agent exhibit bias as well } \\
\text { as social emotional } \\
\text { behaviours of student. }\end{array}$ & $\begin{array}{l}\text { User requirements and } \\
\text { preferences are not achieved } \\
\text { and this will be sometimes } \\
\text { complex in developing [3]. }\end{array}$ \\
\hline $\begin{array}{c}\text { Supporting Students Working } \\
\text { Together on Math with Social } \\
\text { Dialogue [7]. }\end{array}$ & $\begin{array}{c}\text { Students will provide } \\
\text { collaboration between them. }\end{array}$ & $\begin{array}{l}\text { This framework gives fast } \\
\text { development of combined } \\
\text { systems of students for } \\
\text { education. }\end{array}$ & $\begin{array}{l}\text { This would be more complex in } \\
\text { developing and deploying into } \\
\text { student systems. }\end{array}$ \\
\hline $\begin{array}{l}\text { Mobile Learning with Bluetooth- } \\
\text { based E-Learning System [10]. }\end{array}$ & $\begin{array}{l}\text { Bluetooth technology is used } \\
\text { for connecting to the network } \\
\text { instantly. JABWT Java API } \\
\text { [10] for Bluetooth Wireless } \\
\text { Technology. }\end{array}$ & $\begin{array}{l}\text { This is used for reducing } \\
\text { overflow of control } \\
\text { packets and provides } \\
\text { scalability. }\end{array}$ & $\begin{array}{l}\text { More disconnection will be } \\
\text { there. Communication cannot } \\
\text { be out of range. }\end{array}$ \\
\hline $\begin{array}{l}\text { Constructing a Cluster-Based M- } \\
\text { Learning Architecture in Mobile } \\
\text { Ad Hoc Networks Using MPEG-21 } \\
{[11] .}\end{array}$ & $\begin{array}{l}\text { MPEG-21 methods are used } \\
\text { for dynamic learning. Cluster- } \\
\text { dependent } \quad \text { M-Learning } \\
\text { architecture is defined [11]. }\end{array}$ & $\begin{array}{l}\text { This is used for reducing } \\
\text { overflow of control } \\
\text { packets and provides } \\
\text { scalability. }\end{array}$ & $\begin{array}{l}\text { Students cannot be affordable to } \\
\text { have this multimedia platform } \\
\text { and MPEG-21 [11] has some } \\
\text { security problems. }\end{array}$ \\
\hline
\end{tabular}

\section{CONCLUSION}

In this paper, survey on m-learning such as m-learning definition, evolution, benefits, how it is used in present context and technologies that are used for m-learning is discussed. What is the role of different networking technologies used for m-learning, comparative survey on different architectures, design approaches and technologies are mentioned. Their merits and demerits also described clearly. This study makes the people to know the existing place of m-learning in the present scenario. Future work for this study proposes m-learning to efficiently use in convenient environments and modifications that should be made for developing m-learning rapidly by considering above factors.

\section{ACKNOWLEDGEMENT}

It is with great pleasure, deep satisfaction, and gratitude that I acknowledge the contributions of several individuals towards the successful completion of this project. I would like to thank Prof. H. Santhi Asst. Prof., School of Computing Sciences, VIT University, for his guidance, assistance and unremitting support over the last nine months. She has always been present to guide me and provide his insight on all the technical and non-technical aspects of this paper work. I am very grateful to Dr. N. Jaisankar, Program Manager, School of Computing Sciences, VIT University, for his care, assistance and enthusiasm throughout our studies as our beloved Manager. I also express my special thanks to my beloved Parents for their splendid cooperation and support all throughout my course work. Last but not least, I would like to thank the Staffs of School of Computing Sciences, Vellore
Institute of Technology, and my friends for comments and suggestions provided to me at every phase of the project.

\section{REFERENCES}

[1] Lavare Henry, Suresh Sankaranarayanan, "Intelligent Agent based Mobile Learning System" International Journal of Computer Information Systems and Industrial Management Applications (IJCISIM) ISSN: 2150-7988 Vol.2, 2010.

[2] Bj.Hedin, E. Lindgren, "Mobile Learning: A Comparison of Presentation Methods for Reading on Mobile Phones ", proc. IEEE distributed systems, 2007.

[3] Vanja Garaj, "m-Learning in the Education of Multimedia Technologists and Designers at the University Level: A User Requirements Study", IEEE TRANSACTIONS ON LEARNING TECHNOLOGIES, VOL. 3, NO. 1, JANUARY-MARCH 2010.

[4] R. Kumar, C.P. Rose, M. Joshi, Y.C. Wang, Y. Cui, and A. Robinson, "Tutorial Dialogue as Adaptive Collaborative Learning Support", Proc. Artificial Intelligence in Education (AIED '07), 2007.

[5] S. Chaudhuri, R. Kumar, M. Joshi, E. Terrell, F. Higgs, V. Aleven, and C.P. Rose, "It's Not Easy Being Green: Supporting Collaborative Green Design Learning," Proc. Intelligent Tutoring Systems (ITS'08), 2008.

[6] H. Ai, R. Kumar, D. Nguyen, A. Nagasunder, and C.P. Rose, "Exploring the Effectiveness of Social Capabilities and Goal Alignment in Computer Supported Collaborative Learning," Proc. Int'l Conf. Intelligent Tutoring Systems (ITS'10), 2010. 
[7] R. Kumar, G. Gweon, M. Joshi, Y. Cui, and C.P. Rose, "Supporting Students Working Together on Math with Social Dialogue," Proc. Workshop Speech and Language Technology in Education (SLATE '07), 2007.

[8] Alf Inge Wang, Michael Sars Norum, Carl-Henrik Wolf Lund, "A PEER-TO PEER FRAMEWORK FOR MOBILE COLLABORATION", Dept. Of Computer and Information Science, Norwegian University, 2007.

[9] D. Bohus and A.I. Rudnicky, "The RavenClaw Dialog Management Framework: Architecture and Systems," Computer Speech and Language, vol. 23, no. 3, pp. 332$361,2009$.

[10] Yonghong Zhang, Shiying Zhang, Son Vuong, Kamran Malik, "Mobile Learning with Bluetooth-based Elearning System", University of British Columbia, 2006.

[11] Hua-Yi Lin, Zhi-Ren Qiu, De-Jun Pan, and Xin-Xiang Zha, "Constructing a Cluster-Based M-Learning Architecture in Mobile Ad Hoc Networks Using MPEG21", Fifth IEEE International Conference on Computational Science and Applications, 2007.

[12] Attewell, J., "Mobile Technologies and Learning: a Technology Update and MLearning Project Summary", Learning and Skills Development Agency, 2005.

[13] Kineo and UFI, "Mobile Learning Reviewed", Learndirect, 2009.
[14] Paul B. Muyinda, "MLearning: pedagogical, technical and organisational hypes and realities", Campus-Wide Information Systems Vol. 24 No. 2 pp. 97-104, 2007.

[15] Meisam Hejazinia, Mohammad Reza Razzazi, "MLearning System over MANET on Mobile phones", 4th International Conference on Distance Learning and Education (ICDLE), 2010.

[16] A Pongpech, S.W Sadiq, Ma. E. Orlowska, "On Using Workflow Technology to model eLearning Process", Proc. Eighth IEEE International Conference on Advanced Learning Technologies 2008.

[17] Neil McLean, "The M-Learning Paradigm: an Overview", IMS Australia Macquarie University, Sydney, 2003.

[18] Vasiliou, A. And Economides, A.A., "Mobile collaborative learning using multicast MANETs", Int Journal of Mobile Communications, Vol. 5, No. 4, pp.423-444, 2007.

[19] Sourish CHAUDHURI, Rohit KUMAR, Iris HOWLEY and Carolyn Penstein ROSE, "Engaging Collaborative Learners with Helping Agents", Proc. Artificial Intelligence in Education (AIED '09) Carnegie Mellon University, 2009. 